\title{
Of faces seen, unseen, and behind the
}

\section{scenes}

Patricia K. Baskin, MS, Executive Editor

Robert A. Gross, MD, $\mathrm{PhD}, \mathrm{FAAN}$, Editor-in-Chief

Correspondence to Ms. Baskin: pbaskin@neurology.org

Neurology ${ }^{\circledR} 2013 ; 80: 2-4$
FACES OF THE PRINT AND ONLINE JOURNAL With this issue, we introduce you to the new face of $N e u r o l o g y{ }^{\circledR}$. In future issues, we will use the window on the cover to showcase an image from an article within the issue or a submission to our Visions section. Some may wish to retain our current format, but there are practical reasons for removing the Table of Contents from the cover (the increasing need to truncate titles and bylines). We are excited about a design that sets each issue apart and transfers well to electronic media-particularly the iPad. At some point, we hope to create interactive figures and titles on the covers of the journal in our iPad version. A few articles of interest remain on the cover, which in the future will be personalized for each reader's interest.

The face of our Web site will also be changing, along with new functionality to make the browsing and content discovery experience easy and pleasant. The new Web site will debut at the Annual Meeting in March in San Diego; plan on visiting the journal booth at Academy Central to see our newest features demonstrated.

FACES OF OUR AUTHORS Transparency. Neurology strives to maintain the highest level of integrity and transparency in scientific publication. We require authors to follow stringent authorship criteria by divulging their contributions to the published works and disclosing all possible sources of bias. We publish complete author disclosures online, with the most pertinent disclosures listed within the article; by so doing, we create trust from readers, who then have an understanding of each author's contribution to the study and are able to judge for themselves whether bias exists. Our authorship criteria eliminate ghost authors and guest authors - and make the faces of those employed by writing and pharmaceutical companies visible, letting readers know who may have influenced or paid for the studies and their reporting. ${ }^{1-5}$ As the Neurology Information for Authors states:

Neurology defines an author as a person who has made a substantive intellectual contribution to the submitted manuscript. A substantive contribution includes one or more of the following:

- Design or conceptualization of the study

- OR analysis or interpretation of the data

- OR drafting or revising the manuscript for intellectual content

Professional writers employed by pharmaceutical companies or other academic, governmental, or commercial entities who have drafted or revised the intellectual content of the paper must be included as authors. ${ }^{6}$

All those qualifying for authorship must indicate their specific contributions and make full disclosure of all potential sources of bias. Before we instigated this policy, many who fulfilled our new criteria were unlisted, unseen members of the groups or organizations responsible for the articles.

Quality. Neurology requires the highest quality of reporting, including description of sample sizes, methods of randomization, and handling of data. We follow a number of guidelines curated by the EQUATOR Network, an "international initiative that seeks to improve reliability and value of medical research literature by promoting transparent and accurate reporting of research studies." By following the guidelines, authors report essential features of a study that pertain to quality of design and analysis, thereby assuring quality and reproducibility. Guidelines include the CONSORT checklist and flow diagram for randomized controlled trials; the PRISMA statement for systematic review of meta-analyses of randomized trials; the STARD checklist for studies of the accuracy of diagnostic tests; and STROBE for cohort, case-controlled, and cross-sectional studies, all observational human studies, and retrospective data collection studies. For genetic association studies, authors must submit the STREGA checklist. We are working with other stakeholders to increase the quality of reporting in Alzheimer disease studies and to optimize the predictive value of preclinical research. ${ }^{8}$

Originality. A major goal of scientific publication is novelty. Among our editors' tasks is ensuring that accepted

From the American Academy of Neurology (P.K.B., R.A.G.), Minneapolis, MN; and Strong Epilepsy Center and University of Rochester Medical Center (R.A.G.), Rochester, NY.

Go to Neurology.org for full disclosures. Funding information and disclosures deemed relevant by the authors, if any, are provided at the end of this editorial. 
articles contain original material and not material published elsewhere, which may violate copyright or publishing ethics. Inadvertent duplication and plagiarism have become more common in the digital age given the ease of cutting and pasting from earlier work. Neurology has joined other journals in using a software tool created by CrossRef ${ }^{9}$ to check for overlap in submitted manuscripts. CrossRef maintains an extensive database of published scientific articles. Before accepting a paper for publication, Neurology will compare it against published articles in the CrossRef database to see if overlap exists. We may ask for minor revisions if the CrossRef report indicates minor amounts of recycled text, especially in the Methods and Introduction sections, so that we are not violating copyright. Larger amounts of duplicated material may require more major revision; obviously, manuscripts with excessive duplication in the Results and Discussion sections will be rejected.

FACES OF THE PEOPLE BEHIND THE SCENES There is a tremendous editorial effort in creating a weekly medical journal. Besides the editor-in-chief, deputy editor, and 9 associate editors who handle the adjudication of peer-reviewed manuscripts, the masthead lists a plethora of section editors, who are responsible for specific portions or features of Neurology; editorial board members, who provide a high volume of manuscript reviews; and our phenomenal staff of 9, who are the backbone of our operation.

The masthead tells only a snippet of the story. Dr. Mitchell Elkind, listed as the Resident \& Fellow (R\&F) Section editor, heads a separate editorial group of 16 residents and fellows (selected from a list of nearly 100 who apply annually) (appendix 1). They review articles for this online-only portion of the journal, and are responsible for innovative features such as the Journal Club, Mystery Cases, and e-Pearls, among others. The $\mathrm{R} \& \mathrm{~F}$ Section is superbly staffed by Managing Editor Kathleen Pieper, Production Editor Sandra Moriarity, and Editorial Associate Robert Witherow. Dr. Ted Burns, the Podcast editor, has a panel of 48 neurologists who suggest interviewees and write scripts, taking part in the weekly podcasts that feature interviews of authors of Neurology articles and the Lessons of the Week (appendix 2). Production Editor Sandra Moriarity spends hours scheduling interviews with interviewees around the world and making sure recordings are of high quality and ready to be edited by Robert Rook and other members of the technical team at the American Academy of Neurology.

Dr. John Corboy, the editor of Neurology ${ }^{\circledR}$ Clinical Practice, has 3 associate editors and is assisted by Neurology Clinical Practice Managing Editor Sharon Quimby and Editorial Associate Lee Ann Kleffman. The feature figures for Dr. Eduardo Benarroch's Clinical Implications of Neuroscience Research articles are fashioned by Graphics Editor Cynthia Abair, who also edits other authors' figures so that they appear in the best possible light. CME examinations for journal articles are written by Drs. Steven Lewis and James Owens, and by Dr. Ted Burns for podcasts: they are ably edited by Lee Ann Kleffman, who also checks the final page proofs of all articles before publication. The Global Perspectives articles, written or procured by Drs. Johan Aarli and Oded Abramsky, are coordinated and edited by Kathleen Pieper. Drs. Christopher Boes and Kenneth Mack are assisted by Morgan Sorenson in viewing books and assigning book reviews. Drs. Steven Karceski, David Spencer, and Robert Griggs edit the Patient Pages and the WriteClick sections, with staff help from Kathleen Pieper and Morgan Sorenson. Dr. Anne McCammon reviews the Reflections articles; the authors of those contributions record audio versions for the iPad with the help of Karen Skaja. Dr. Robert Daroff steps in as needed when a scientific integrity issue arises. The faces of our many faithful and thoughtful reviewers remain unseen to the authors, but we have listed those who reviewed for us during the past half year elsewhere in this issue.

Staff manages the peer review for the nearly 100 manuscripts submitted each week, making sure submissions are complete, forms are filled out, permissions gathered, editorialists invited, and myriad questions from authors and reviewers answered. The efforts continue when manuscripts are forwarded to Alex Lazerow and Steve Rose at our publishing house, Lippincott Williams $\&$ Wilkins, where papers are copyedited and proofs sent to authors for review before final printing. Finally, the digital files are included in the iPad app at Lippincott Williams \& Wilkins and sent to HighWire Press in Stanford, California, for posting on the Neurology.org Web site. Our heartiest thanks go out to our team and, importantly, to Kim Jansen, our publisher at Lippincott Williams \& Wilkins, who works with us to coordinate journal policies, projects, and processes.

\section{DISCLOSURE}

Patricia K. Baskin, MS, is Executive Editor of Neurology and employed by the American Academy of Neurology. Her spouse is employed by the Department of Veterans Affairs and University of Washington and receives research funding from the Department of Veterans Affairs and NIH. He is an Associate Editor of Endocrinology and Executive Editor of Journal of Histochemistry and Cytochemistry and receives stipends for those activities. Ms. Baskin received reimbursement for travel expenses to 2 meetings in 2011 of The International Publication Planning Association (TIPPA), an association of industry professionals sponsored by Pharmaceutical Education Associates LLC, to present Neurology's authorship policies, and consulted with no stipend or reimbursements for the Medical Publishing Insights and Practices initiative at a journal-pharma workshop in 2011 and one TIPPA meeting in 2012.

Robert A. Gross, MD, PhD, FAAN, has received research funding from the Department of the Army and UCBPharma. He is supported for educational endeavors from the University of Rochester Medical Center's Clinical and Translational Science Award from the NIH. Dr. Gross has conducted clinical trials over the past 5 years funded by GlaxoSmith Kline, UCB, Ortho-McNeil, Pfizer, and Marinus. He has served on the 
speakers' bureaus for Abbott, UCB, and GlaxoSmithKline and has received consultant fees from GlaxoSmithKline and Harris Interactive. Since his appointment as Editor-in-Chief, Dr. Gross has ceased participation in industry-sponsored clinical trials and speakers' bureaus. $\mathrm{He}$ receives an honorarium from AAN as Editor-in-Chief of Neurology. Go to Neurology.org for full disclosures.

\section{APPENDIX 1}

\section{Resident \& Fellow Section}

Current Editor: Mitchell Elkind and Deputy Editor John Millichap, and current R\&F editorial team: Audrey Brumback, Daniel Goldenholz, Jeremy Gregory, Dragos Nita, James Park, Peter Pressman, and Roy E. Strowd III. New members joining for 3-year term effective November 2012: Joseph Cahill, Cliff Hampton, Andrea Harriott, Shaheen Lakhann, Matt Lincoln, Andrew Schepmayer, Adam Numis, and Miya BernsonLeung. Thanks to those who recently ended 3-year terms, effective November 2012: Stacey Clardy, Jennifer Fugate, Amy Gelfand, Chafic Karam, Christine Ulane, Victoria Wong, and Holly Yancy.

\section{APPENDIX 2}

\section{Podcast Team}

Current Editor: Ted Burns and Podcast Committee: Michael Benatar, Jeffrey Burns, Ryan Overman, Shanna Patterson, Jason Mackey, Juliana Lockman, and Christopher Boes. Podcast Interviewing Panel: Benjamin Atkinson, Matthew Barrett, Jennifer Bickel, Cyrus Boelman, Julian Bragg, Beau Bruce, Elliot Dimberg, Erik Ensrud, Alberto Espay, Maria Farrugia, Matthew Flaherty, David Geldmacher, Myla Goldman, Justin C. Graff, Adam Heller, Mitchell Isaac, Joanna C. Jen, Mark B. Keegan, Brett Kissela, Michael Knoflach, Peter Konieczny, Jeremy Lanford, Dan Larriviere, Michael Levy, Farrah Mateen, Brandy Matthews, Michelle
Mauermann, Michael Melanson, John Morgan, John Mytinger, Pearce J. Korb, Karen Roos, Justin Sattin, Aman Savani, Lori A. Schuh, Guillermo Solorzano, Andy Southerland, Michael Sowell, Jeff Waugh, Matthew Wong, and Chenjie Xia.

\section{REFERENCES}

1. Baskin PK, Gross RA. Honorary and ghost authorship. BMJ 2011;343:d6223.

2. Baskin PK, Knopman DS, Gross RA. Conflicts of interest, authorship, and disclosures in industry-related scientific publications. Mayo Clin Proc 2010;85:196-197.

3. Knopman DS, Baskin PK, Pieper KM, Quimby SL, Gross RA. Reporting potential bias: Neurology's evolving policies. Neurology 2011;11:110-112.

4. Schwid SR, Gross RA. Bias, not conflict of interest, is the enemy. Neurology 2005;64:1830-1831.

5. Megerian JT. Reporting potential bias: Neurology's evolving policies. Available at: http://www.neurology.org/content/76/2/110. full/reply\#neurology_el_42330. Accessed November 10, 2012.

6. Neurology Information for Authors. Available at: http: //www.neurology.org/site/misc/auth2.xhtml. Accessed November 10, 2012.

7. EQUATOR Network Guidelines. Available at: www.equatornetwork.org. Accessed November 10, 2012.

8. Landis SC, Amara SG, Asadullah K, et al. A call for transparent reporting to optimize the predictive value of preclinical research. Nature 2012;490:187-191.

9. Crossref. Available at: www.crossref.org. Accessed November 10, 2012. 


\title{
Neurology
}

\author{
Of faces seen, unseen, and behind the scenes \\ Patricia K. Baskin and Robert A. Gross \\ Neurology 2013;80;2-4 \\ DOI 10.1212/WNL.0b013e31827de9e6
}

This information is current as of December 24, 2012

\section{Updated Information \&} Services

References

Permissions \& Licensing

Reprints including high resolution figures, can be found at: http://n.neurology.org/content/80/1/2.full

This article cites 5 articles, 2 of which you can access for free at: http://n.neurology.org/content/80/1/2.full\#ref-list-1

Information about reproducing this article in parts (figures,tables) or in its entirety can be found online at:

http://www.neurology.org/about/about_the_journal\#permissions

Information about ordering reprints can be found online:

http://n.neurology.org/subscribers/advertise

Neurology $®$ is the official journal of the American Academy of Neurology. Published continuously since 1951 , it is now a weekly with 48 issues per year. Copyright (C 2012 American Academy of Neurology. All rights reserved. Print ISSN: 0028-3878. Online ISSN: 1526-632X.

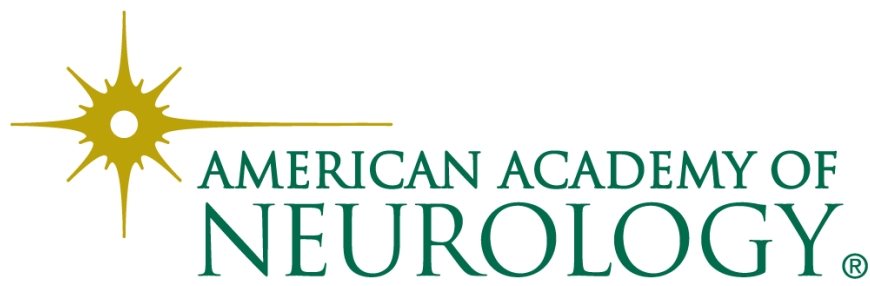

